Meta

Journal des traducteurs

Translators' Journal

\title{
An Approach to Interface Terminology: The Example of Environmental Economics in English as a Foreign Language
}

\section{Catherine Resche}

Volume 45, numéro 4, décembre 2000

URI : https://id.erudit.org/iderudit/003941ar

DOI : https://doi.org/10.7202/003941ar

Aller au sommaire du numéro

Éditeur(s)

Les Presses de l'Université de Montréal

ISSN

0026-0452 (imprimé)

1492-1421 (numérique)

Découvrir la revue

Citer cet article

Resche, C. (2000). An Approach to Interface Terminology: The Example of Environmental Economics in English as a Foreign Language. Meta, 45(4), 628-645. https://doi.org/10.7202/003941ar

\section{Résumé de l'article}

$\mathrm{Au}$ fur et à mesure que les sciences évoluent et empruntent les unes aux autres pour élargir leur champ d'action, la terminologie d'interface représente un défi grandissant pour tous ceux qui travaillent dans des domaines qui se situent à la croisée des chemins de plusieurs disciplines. Cette étude pose la question de la définition de la zone d'inter-face et a pour but d'analyser les conditions nécessaires à une sélection cohérente de termes ayant trait à l'interface. Après un bref retour sur la théorie de la terminologie et un plaidoyer pour une plus grande flexibilité, elle s'intéresse aux aspects pratiques en prenant pour exemple l'économie de l'environnement. Le public cible, composé d'étudiants français de deuxième année en sciences économiques, permet de souligner la nécessité d'adapter la sélection en fonction de la situation. Une terminologie d'interface toute faite n'est pas concevable. Cette conclusion vaut, de toute évidence, pour d'autres utilisateurs tels que les traducteurs, les interprètes ou les terminologues. 


\title{
ÉTUDES TERMINOLOGIQUES ET LINGUISTIQUES
}

\section{An Approach to Interface Terminology: The Example of Environmental Economics in English as a Foreign Language}

\author{
CATHERINE RESCHE \\ Université de Paris II-Panthéon-Assas, Paris, France
}

\begin{abstract}
RÉSUMÉ
Au fur et à mesure que les sciences évoluent et empruntent les unes aux autres pour élargir leur champ d'action, la terminologie d'interface représente un défi grandissant pour tous ceux qui travaillent dans des domaines qui se situent à la croisée des chemins de plusieurs disciplines. Cette étude pose la question de la définition de la zone d'interface et a pour but d'analyser les conditions nécessaires à une sélection cohérente de termes ayant trait à l'interface. Après un bref retour sur la théorie de la terminologie et un plaidoyer pour une plus grande flexibilité, elle s'intéresse aux aspects pratiques en prenant pour exemple l'économie de l'environnement. Le public cible, composé d'étudiants français de deuxième année en sciences économiques, permet de souligner la nécessité d'adapter la sélection en fonction de la situation. Une terminologie d'interface toute faite n'est pas concevable. Cette conclusion vaut, de toute évidence, pour d'autres utilisateurs tels que les traducteurs, les interprètes ou les terminologues.
\end{abstract}

\begin{abstract}
Interface terminology will increasingly become a challenge for anyone working in disciplines that lie at the crossroads of several fields. Indeed, sciences continue to evolve, broaden their scope and, hence, borrow from one another. This study raises the problem of defining the boundaries of what constitutes an interface, and then studies the conditions for the selection of relevant terms. After reviewing some theoretical aspects of terminology science and calling for a more flexible approach, it examines some practical questions through the case of environmental economics. The target public-consisting of second-year French university students of economics-provides the opportunity to stress the need for the teacher to adapt the selection of interface terms to the situation. The conclusion, i.e. that there is no such thing as a ready-made stock of interface terms, could also be applied to translators, interpreters, terminologists and other potential users of such terminology.
\end{abstract}

\section{MOTS-CLÉS/KEYWORDS}

interface terminology, environmental economics, English as a foreign language, methodology, problems

\section{INTRODUCTION}

'Terminology' is a challenging term which can either describe a field of activity, its theoretical underpinning or a set of terms pertaining to a specific field of activity. Actually, it is possible to speak of 'the terminology of terminology'. In the title of this 
study, we obviously use 'terminology' with the third meaning in mind, i.e. terms. However, this does not exclude a short discussion of theoretical aspects.

Terminology involves various participants: professors and researchers, translators and interpreters, linguists and technicians, terminologists, students... All are connected with the field of terminology to varying degrees, with different motivations and needs. Some observe, analyse and record terms, others suggest, create, recommend or standardise them; still others may just consider them from the practical angle of users in need of reliable tools to communicate according to the norms prevailing in a given field. Obviously, the different groups will have different approaches. Whatever the reasons, whoever gets involved in terminological activities can justifiably do so as long as the method is clearly explained and the goal explicitly stated.

The particular approach to terminology which we would like to discuss in this paper was born of interest for the field as well as necessity, which accounts for the theoretical and practical aspects of our study. By 'interface terminology', we refer to a set of terms resulting from the interconnection of disciplines which are not normally perceived as contiguous, as illustrated in our example. This phenomenon raises two main questions. The first is how and where to set the limits for the stock of terms which we designate by the term 'interface terminology'. The other is whether the boundaries, once defined, should be considered stable or if they can and should fluctuate.

We feel that, in spite of the fact that we illustrate our proposal by using a specific branch of economics, i.e. environmental economics, the principles and methods mentioned in the course of our analysis can also apply to other fields, in other circumstances. Once adapted, we hope this methodology can be useful to translators and terminologists as well. After reviewing the theoretical and methodological aspects of the question, we discuss the practical steps we have taken in order to perform the most accurate selection possible of interface terms in the field of environmental economics for the target public. The experience we have acquired from the problems encountered may shed new light on how to approach this particular category of terms.

\section{THEORETICAL AND METHODOLOGICAL ASPECTS}

\subsection{For a Flexible Theory of Terminology}

One cannot talk about theory without referring to Eugen Wüster, the author of The Introduction to the General Theory of Terminology (1979) and founder of the Vienna General Theory of Terminology, known as VGTT. As Felber (1981: 70) underlines, E. Wüster himself, quite interestingly, defined terminology as "an interdisciplinary field of linguistics, logic, ontology, information science and individual subject fields."

Terminology itself is thus a perfect illustration of a discipline lying at the interface of several fields.

The Austrian engineer, however, was not as interested in the strictly linguistic aspects of terminology as in the need to determine the accurate structure which organises scientific concepts at a given time. Initially, then, the starting point was a concept which was designated by means of a term. Establishing the links between concepts helped to conceive of fields in a logical way and it was important for terms 
to be selected and organised so as to reflect the structure of particular fields. Terms were supposed to refer to specific notions or objects and to be univocal.

Understandably, it is important for terms referring to techniques, objects, tools, etc. to be used uniformly. This would make life easier for a given community of specialists which is representative of a specific field, and ensure easy communication as well as avoid waste of time, energy and money resulting from misunderstandings and ambiguity. We have chosen to make this brief survey of the initial theory in order to highlight how this theory works in an idealised way and to point out how the situation may vary from one specialised field to another. Indeed, the theory may be easier to apply to technical areas and exact sciences than in the context of social sciences (Resche 2000). Actually, in the sixty years since Wüster first set forth his fundamental principles, criticism has been levelled at his theory for being too rigid and overlooking the linguistic aspects of LSPs. The strict division between fields has been questioned and the notion of concept re-examined (Humbley 1998: 139).

This does not mean, however, that one should reject the theory altogether, since that would doom terminology forever: a dose of rigour is essential. Still, in order to address the particular problems of individual subject fields, it seems that Wüster's guiding principles should be reinterpreted and adapted. Designating objects, tools or concepts via a rigorous denomination in order to establish and unify the terminology of a specialised field is one thing. Deciding which terms will be most helpful for a given public with specific purposes is another. The latter approach obviously requires more flexibility and the resulting selection is likely to encompass a larger set of terms. We may also wonder if, under some circumstances, certain concepts might not be taken for granted so that terms could be considered as a starting point. In other words, let us imagine a situation in which students studying a second language from the perspective of a specific terminology are already familiar with the concepts and notions of the field in their mother tongue. In that case, though it is advisable to compare the notional content from one language to the other whenever necessary, systematically starting with concepts may prove superfluous.

It goes without saying, however, that for a language teacher who is not a specialist of economics, it would be unthinkable not to rely on concepts to start with. The end-product, the selected terms, will be the result of his analysis of the conceptual links. If this is a necessary condition, it is not, however, sufficient. Working with two languages may make it necessary to consider a larger stock of terms on a particular subject. Terms that are taken for granted in the mother tongue will have to be mastered in the foreign language, if only to avoid generating approximation.

This brings us to our second point, namely the functional aspect of LSPs. According to the Prague School (Drodz 1981: 109), "an LSP has to fulfil specific communicative needs within special fields of human activity."

Thus, terms will become the tools that help to meet these needs. From the point of view of a teacher who is in charge of selecting relevant terms, those which are to be used and learnt by the students, it is essential to let this functional aspect drive the term selection process.

Accordingly, and this is our third point, before any serious work in terminology can be achieved, it is important that some preliminary conditions be fulfilled, i.e., as Robert Dubuc (1981: 573) points out, that the target public and its needs be clearly identified. Only then will it be possible to compile the appropriate corpus that will 
serve as a basis for the selection of the relevant terminology. An accurate assessment of the situation will determine the degree of technicality to seek and thus, the volume of terms to work with.

\subsection{Assessment of the Situation}

\subsubsection{The Target Public and its Needs}

As far as we are concerned, the notion of interface is one that applies perfectly to our teaching experience. First, as teachers of English to French students, we experience the interface of two languages. In addition, our public consists of university students in economics, and this creates a second level of interface-English is not their major subject. Finally, we make it our duty in our English classes to reflect the variety of themes covered in the general economics courses. As economics is itself an interface discipline, we are very often confronted with the difficult task of selecting an adequate interface terminology, one which will best fill the needs of our students.

What are those needs? They may vary, depending on whether we deal with second-year students or post graduates. The common denominator, though, is that they all need to read reference books in English and become familiar with the specialised terms they come across. Some will find jobs in the field of economics, in which case being able to communicate in English, whether orally or through notes or reports, will be absolutely necessary. Some may even be led to translate official documents. As for those who choose to follow post graduate studies, if they want to gain recognition in their field of research, they will have to master the art of writing abstracts, articles, and of giving lectures in English. So, using the appropriate terms and phrases in the right context is vital. Clearly, our task consists of taking these various requirements into consideration and of adapting the level of specialisation of the terminology we select to our public. In the present example, that of environmental economics, our public is composed of second year university students and our corpus was chosen accordingly.

\subsubsection{The Corpus}

It was only natural to start with a source that was adapted to our students-namely a textbook widely used by their American counterparts-in order to examine what terms emerged as central to the theme. Our choice went to Paul Samuelson's worldfamous Economics, which, in the 1998, sixteenth edition, devotes a chapter to "Protecting the Environment." Incidentally, it is worth noting that the index of such a textbook can help judge the importance of a term from the number of pages indicated next to the key words; it is a reliable barometer of the frequency of use of these terms and it can serve as a basis for further investigation.

In order to supplement the information we could get from the textbook approach, we looked at the academic literature on the subject. Our goal was to check whether researchers addressing fellow specialists used a range of terms that differed from those chosen for didactic purposes. The easiest way to survey a large number of recent books was to refer to the specialised catalogues provided by the main publishers in the field of economics over the past two years (See Additional References). 
Many of these catalogues include abstracts which offer a reliable source of key terms; here again, recurring terms can be a useful reference point. Our third and last source of information was the economic press (The Economist, Business Week), where we often find the sort of articles that can be used in class with our students. These offer a compromise between specialised fields with their highly-specialised terms and a more general approach aimed at a larger readership.

Needless to say that the corpus, in such a case, is a twofold source of information. On the one hand, it enables the teacher-or the translator, for that matter-to gather background information on the notions and concepts of the special area that may not be so familiar to him. It also provides precious indications as to the logical links that organise these concepts in relation to one another. This helps to establish a notional map of the field. On the other hand, the corpus must be re-read with a view to collecting the corresponding terms. We shall follow this order in our approach to the interface terminology in environmental economics.

\section{ENVIRONMENTAL ECONOMICS: PRACTICAL ASPECTS}

\subsection{Preliminary Remarks}

Before considering the particular branch of environmental economics that will illustrate the problems raised by interface terminology, we find it useful to take a closer look at each of the two disciplines involved. Actually, they are themselves at the intersection of a number of fields. As we mentioned already, economics borrows from many other disciplines as shown in Figure 1, though we cannot claim to provide an exhaustive presentation.

Fig. 1: Economics and connected fields

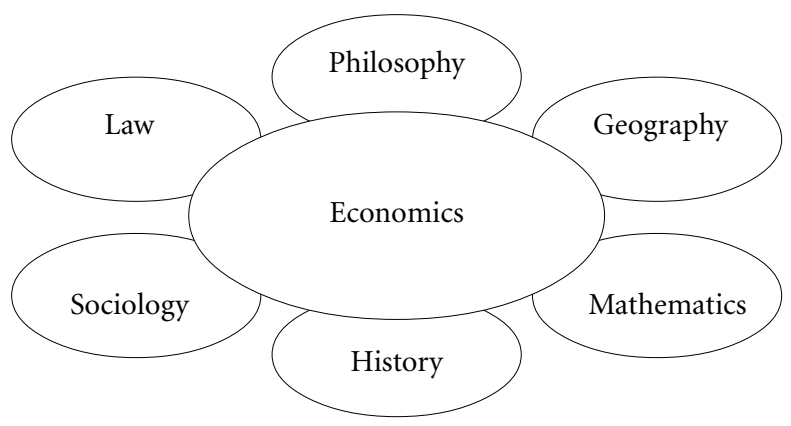

As for environmental studies, they are directly linked with geography, geology, biology, ecology, to name but a few.

The obvious question that comes to mind when one considers an interface discipline is whether the theory according to which the whole is equal to the sum of its constituent parts can be verified. If so, our preoccupation with interface terminology would be vain, as the terms of one discipline would just be added to those of the other discipline. There would be no problem to solve! Actually, for a long time, this problem could not even be raised for the simple reason that the theory of terminol- 
ogy recommended that fields be strictly separated and divided into subfields, if necessary, to avoid any overlapping. However, problems are increasingly considered in an extensive way, perhaps as a result of the current context of globalisation and its lesser-known but just as essential counterpart-localisation. As sciences are evolving at a rapid pace, the need for interface terminology will be felt more and more acutely by the specialists and users concerned.

As regards environmental economics, interface terminology cannot be viewed as a no man's land between the two disciplines (Figure $2 a$ ); actually, it refers to a common ground which has become part of each of the original disciplines, enriching it by broadening its scope, as illustrated in Figure $2 b$ :

Fig. 2a: Interface as a no man's land

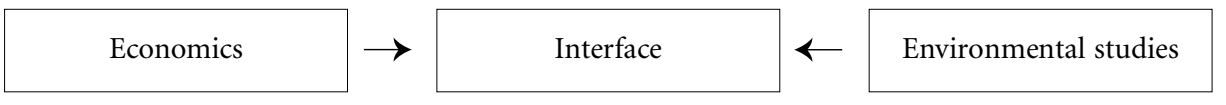

Fig.2b: Interface as a common ground

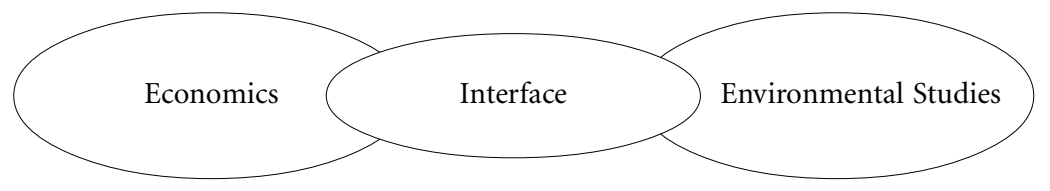

Let us be clear about the notion of common ground: it remains to be seen whether 'common' is to be taken as an indication that the interface terminology will be exactly the same in all situations. This question will be examined later; for the moment, we shall assume that 'common' designates an existing link between the two disciplines. Both economics and environmental studies include an additional field which allows them to consider present-day problems from a new angle.

In this respect, the example of game theory is quite telling (Damaso 1996: 182183). Game theory originated in the field of mathematics; its pioneers were Ernst Zermello in 1912, Emile Borel between 1921 and 1927, and John Von Neumann in 1928. However, it was only in 1944 that the hypotheses emerged as a theory, thanks to the joint research of Von Neumann, the mathematician, and Oskar Morgenstern, an economist. In their book Theory of Games and Economic Behaviour, they used game theory to develop a theory of economic behaviour. Later, John Nash added a major contribution, for which he was awarded the Nobel Prize in economics. Characteristically, our corpus evidenced links between environmental economics and game theory. What this clearly indicates is that the notion evolved outside of its original sphere and was enriched in the process.

The second point we would like to make here as regards the selection of interface terminology in a foreign language is the need to constantly steer clear of two major pitfalls, which can be called 'noise' and 'silence' (Dubuc 1981: 576). 'Noise' refers to the danger of overcrowding the set of terms with parasites that cause the list of terms to be uselessly long and tedious. The term 'silence' describes the opposite situation, 
where harmful information gaps result from the failure to identify and select a significant number of useful terms. Both cases point to the inadequacy of the selection for the target public. The way to avoid such flaws is to optimise use of the background information contained in the corpus itself. This should act as a safeguard.

\subsection{Collecting the Background Information}

We have no real expertise in economics, but, by just relying on our logical reasoning and our general experience, we could assume, from the beginning, that such fields as population growth, economic growth, industrialisation, consumption and market sources would be likely candidates for an interface between economic and environmental concerns. These assumptions, however, require verification and we trusted our corpus to give us more detailed information on the subject. This would help us to understand the links and organise them in a more structured way (see Appendix 1). We felt that cross-examining our different sources would provide a more accurate picture of this rapidly evolving branch of economics:

The discipline of environmental and resource economics has undergone a rapid evolution over the past three decades with the early literature focusing mainly on valuation and the design of policy instruments to correct externalities and encourage optimal resource exploitation. In the past few years, the field has broadened its scope by making numerous links with other disciplines in economics as well as the natural and physical sources. (Folmer and Tietenberg 1997)

This seemingly general statement contains key notions-for example, the association of resource and environmental economics and their interdependence. Also, technical terms which need to be examined more closely, by referring to the textbook explanations, are introduced.

Specifically, before dealing with environmental economics proper, Paul Samuelson reviews the problems of population and resource limitations, and refers to naturalresource economics. These considerations are indispensable if one is to understand environmental economics. We are thus shown the links between growth and resource limitation and the relationships between population, economic development, living standards and pollution. Major concerns emerge such as the challenging question of whether technology, economic growth and market forces should be viewed as saviours or villains. In other words, are economic growth and industrialisation the road to environmental ruin and a threat to human health? The role and place of economists in relation to the environment is described by the author as follows:

Generally, economists tend to lie between the environmentalist and the cornucopian extremes, pointing to the importance of a wise combination of market forces and government intervention as key to both environmental survival and continued improvements in living standards. (Folmer and Tietenberg 1997: 322)

Clearly, it would be a mistake to consider that economists and environmentalists agree on all points and work hand in hand to solve environmental problems. One might even consider, at first, that the term environmental economics is an oxymoron, thereby suggesting that the preoccupations of economists and those who aim at the protection of the environment are contradictory. The concerns of environmentalists with the preservation of some rare, endangered species can hardly be said to 
find an echo in the economic goals of efficiency, profitability and productivity! Yet, a closer look at the literature on the subject proves that the situation is not so clear-cut.

Under the succinct heading of environmental economics, the three basic natural resources-land, water and air-are typically viewed as a set of production factors. We understand that, when analysing natural resources, economists distinguish between appropriable ${ }^{1}$ and inappropriable ${ }^{2}$ resources on the one hand, and renewable $^{3}$ and nonrenewable ${ }^{4}$ resources on the other hand. In the definitions of these notions, key concepts such as externalities ${ }^{5}$ and costs and benefits emerge. Examples of nonrenewable and renewable goods are provided. Problems of the allocation of natural resources and the substitutability of natural capital are introduced. The latter term "natural capital" is in itself a wonderful mirror of the interface, as capital here is used in the full economic sense, and explicitly compared to other kinds of capital. The difference between public goods ${ }^{6}$ and private goods ${ }^{7}$ is established in order to illustrate the concept of external effects, and the economic impacts of climate change are examined:

The greenhouse effect is the granddaddy of public good problems; actions today will affect the climate for all people in all countries for centuries to come. (Folmer and Tietenberg 1997: 338)

Definitely considered from an economic point of view, environmental problems and policies are given a market-based approach. Many of the options are then studied in light of a cost-benefit analysis:

An efficient strategy for containing climate change requires weighing the marginal costs of producing $\mathrm{CO}_{2}$ emissions against the marginal benefits. (Folmer and Tietenberg 1997: 339)

What is clearly sought, in the former context, is the "most profitable pollution level." What matters is to evaluate the damages as accurately as possible, especially as regards the threat of global warming. Various and sometimes hotly-debated predictions make it necessary to study the problems of risk and uncertainty and to refer to such theories as game theory or to use the techniques of utility theory under uncertainty ${ }^{8}$, which are familiar to the economic approach. Among the economic solutions reviewed, incentives and deterrents such as tax breaks or fines come as no surprise. Other specific measures, such as the issuing of emissions permits, however, require a more precise explanation'. They also point to the responsibilities of the developed world toward developing countries, and to the need to consider environmental problems from a global point of view.

In addition to the detailed textbook information that can serve as a solid basis for our selection, the academic literature sheds new light on the subject by stressing the more recent developments in research. The notions of sustainable growth and sustainable resource management are approached through the contexts of trade in ivory, timber and forest products. More emphasis is placed on ecological economics, a term which is now used to refer to the economic problems linked with the protection of wildlife and ecosystems, and to the issue of biodiversity loss as well. Increasingly, the interaction between the environment, the economy and society is stressed:

There is a relationship between physical scarcity of environmental resources and the manifestations of scarcity in the forms of rising prices, increasing private costs, social 
and political conflict, and damage to human health and the environment. (JAI Press Inc., Abstract. Hall D.C., 1996, Advances in the Economics of Environmental Resources)

The fact that society as a whole, but also individual economic agents, are involved is clearly established by the press which analyses the attitudes and reactions of households when it comes to sorting their garbage, reducing waste, and acting as responsible citizens. Echoing the latest research on the matter, journalists explain that firms are also turning green, conscious as they are that they should do their best to limit the pollution they cause by carefully monitoring each stage of their production process. Here again, cost-benefit analyses help by revealing that pollution control may turn out to be a wise investment that can improve the bottom line and the firm's image at the same time. Life-cycle analysis (LCA) has now been adopted by a number of manufacturers; it focuses not only on the product's life span but also takes into account the damage by the disposal of that same product. From "cradle-to-grave" analysis, the philosophy has now evolved to "cradle-to-cradle" analysis, stressing on the need to produce recyclable goods whenever possible. The need to integrate environmental concerns within industrial management, the spreading of green accounts, the question of how to use economic models at different levels of government to combat environmental problems and the possibility of projecting environmental trends from economic forecasts, all these concerns emerge from the abstracts of academic studies provided by publishers in the field of economics.

It is not possible, here, to give a comprehensive account of all the background information that a well-documented corpus can offer. Our purpose in presenting the main lines of environmental economics was to show how essential it is for anyone needing to select the proper terms in an interface discipline to understand how, where and why two formerly separate disciplines can come closer and meet.

\subsection{Selecting the Interface Terms}

A main thread runs through the abstracts in our corpus; it is visible through a variety of terms that all draw the reader's attention to the notion of interface. The recurring use of such terms as 'linkages', 'interaction', 'interdependence', 'relationships', and 'collaboration' underlines how unavoidably complex the selection of interface terms may be.

As a cautious start, we therefore decided to limit our choice to the terms that were obviously born of the encounter between economics and environmental studies, which led us to draw up a rather limited list (see Appendix 2). Terms such as 'marketable pollution rights' or 'tradable pollution permits', 'green accounting', 'green taxes', 'eco-auditing', 'natural capital' — to quote just a few-explicitly qualified as candidates, since they perfectly materialised the union between the two disciplines. However, these compound terms did not seem to fully reflect the scope of environmental economics as illustrated by the fields of research announced in the abstracts. A simple confrontation of this initial selection with the titles of the most recent books on the subject (see Appendix 3) was enough to conclude that too restricted a stock of terms might lead to silence or information gaps that would deprive our target public of a number of useful tools to understand and discuss specific subfields. 
Our second move, then, consisted of concentrating on Samuelson's textbook approach and of trusting him to guide us on the path to a more comprehensive choice of appropriate terms. His concrete illustrations of the core concepts and terms served as a basis for a complementary list. For example, we realised that 'log exports' or 'timber trade' required background information and terms such as 'deforestation', 'environmental preservation', or even 'carbon absorption capacity'. Still, we were conscious that the new list was not functional enough and had to be adapted to our second-year public (Lerat 1997: 7). Indeed, the textbook was meant for native speakers, not a French public: our selection definitely needed to be less restrictive. Accordingly, we decided to give additional information as to the collocates that native speakers might take for granted. So, when we refer to interface terminology in the present context, we also include the verbs and phrases that accompany the terms as a rule (see Appendix 4A).

Two important conclusions can be drawn from these observations. The first answers a question we have left open: as the selection has to be tailored to the needs of the public, one cannot imagine a ready-made list of interface terms. Arguably, large term banks, which include millions of terms, might enable users to select one or two sets of terms to reach specific targets, once they have indicated a number of criteria. Still, the indispensable preliminary analysis leading to the choice of filters to be used must be done on an individual ad hoc basis. Many translators who work on documents dealing with transdisciplinary fields are faced with this problem. Most often, they are advised to assess their needs and to compile the relevant terminology before they even start their translation. D. Gouadec (1997: 5) insists that the stock of terms and phrases must be built to meet the specific requirements of a particular translation, even though some sections may be borrowed from formerly established lists or be re-used for future translations. What matters is that each translation be considered as unique and accordingly refer to a unique compilation of terms and phrases. In the context of a class, we can understand the need to consider each text as unique in its analysis of a particular theme, which requires a customised approach as far as terminology is concerned.

Our second conclusion is that there seems to be a trade-off between the background knowledge of the students in their own field of specialisation-economics for students of economics - and the number of terms pertaining to the 'other' discipline they need to master. In other words, the more familiar they are with the principles of economics and the economic approach, the fewer economic terms stricto sensu will appear in the interface terminology, and the more terms dealing with environmental problems they will need. Conversely, students engaged in environmental studies will need to be given a different set of terminological tools-with more items concerning the field of economics, its methods and approach-so that the interface terminology of environmental economics cannot be the same for two categories of students with different backgrounds.

Another point worth considering is that the more fluent the students are in English, the richer their general stock of terms is, and the fewer phrases and collocates they will need to learn. We then have a fluctuating interface terminology which will be coloured differently, depending on the public's background knowledge of the field and proficiency level in English. The degree of technicality will also influence the 
selection. If some students are led to investigate a very precise subfield, they will obviously need a more detailed terminology than those who take a more general approach. It is clear, now, that the stock of interface terms can never be set once and for all, that its main characteristic should be its flexibility. The teacher then has to find a way to answer any specific demand by selecting an interface terminology offering various entry levels.

To materialise the multiple levels, we offer a visual representation (Figure 3). We can imagine a set of elliptical spheres organised around a limited number of easily identifiable terms related to the central notions of the interface (1); this corresponds to our first list in Appendix 2. As we leave the centre and travel towards the periphery, we encounter more and more terms and phrases borrowed from the 'other' discipline, (2, 3 and 4) describing more and more specific aspects of the problems in detail. If we add the areas of these increasingly unfamiliar territories to the initial selection, we end up with a much more comprehensive list of terms. The structure should be flexible enough to enable users to open as many doors as they want in order to visit various sections of the next spheres.

Fig. 3. Multi-level interface terminology

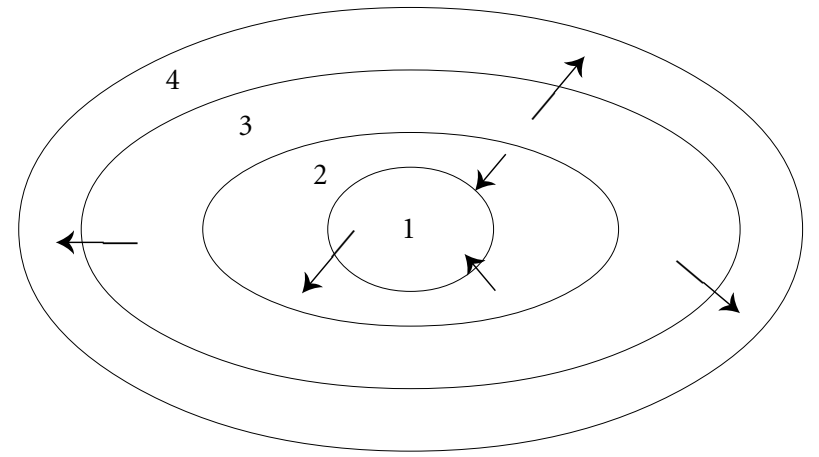

It is important, at this point, to draw the reader's attention to how important the second sphere is for the public in our example. Obviously, the core terms in the centre should and will be the focus of class discussions and analyses. They are indispensable in so far as they describe the essential links between economists' preoccupations and environmental matters. However, second-year French students will only be able to tackle these questions if they have been introduced to the vital, more general terms contained in the second sphere. For this reason, we also have arrows pointing from sphere 2 in the direction of sphere 1, thereby indicating that the starting point, for our public, is likely to be sphere 2 . Once the introductory material has been mastered, they will be able to make the most of the core terms and discuss the notions more adequately. This approach, however, should not be restrictive. Supposing an article introduces a deeper analysis on a specific aspect of environmental economics, a visit to the third sphere might prove necessary (Appendix 4B).

The problem, one might argue, is that when progressing towards the periphery, one may well leave the interface territory. One possible answer could be that our approach to interface terminology and its function surely requires further develop- 
ment. Consider a French post-graduate student in economics or an economist dealing with very specific areas of environmental economics. In the course of his or her research, he or she needs to read reference books in English and, later, may wish to write articles in English. Obviously, the student or the economist must become familiar with the specific terminology pertaining to the environmental aspect under analysis from an economic point of view. In that case, the terms provided by the outer spheres in Figure 3 will become vital. Therefore, they do have their place in the interface terminology corresponding to this degree of extreme specialisation. Students in upper levels can even be trained to select and record the relevant terms of a subfield on their own. Such assignments will help them to understand that there is no room for approximation and guesswork and prepare them to be autonomous in their future research.

Let us now consider a different context, that of training courses for future translators and interpreters in LSPs; it is clear that even the best curriculum cannot include all the possible fields the students will one day be asked to deal with. What matters, in such courses, is to give the students guidelines and methods that will help them to work on their own later (Arntz 1981: 524):

Language training in LSPs can and must only serve as an example, providing the student, in addition to the program subjects, with methodological instruction that is not limited to a certain specialised area and can be applied to other areas.

The problem of interface terminology is one which these students will increasingly have to solve, and the realisation that there are no fixed limits to this territory can only be beneficial; provided they carefully define their focus, rely on their experience, and take stock of their background knowledge and their needs, these future translators and interpreters should be ready to systematically reconsider their criteria with a view to achieving the best-suited selection of terms.

The few examples we have just mentioned illustrate different situations in which the question of interface terminology needs to be addressed in a systematic manner.

\section{CONCLUSION}

Through the example of environmental economics, we have tried to analyse the two fundamental questions of interface terminology. Anyone dealing with discrete fields which intersect at a given, not arbitrary point is first confronted with the problem of how and where to set the limits of the interface. To answer this question, the necessary condition, we argue, is to gain a fair understanding of the interconnections which exist between the fields involved in the interface. This can only be achieved through a thorough analysis of a well-documented, carefully-built corpus. As the links emerge, it is advisable to draw a notional map of the interface in order to visualise how the notions fit in the structure and to make sure that no aspect has been neglected.

Once the interface area has been identified, the problem of the most adequate selection remains. A rigorous assessment of the situation, of the target public's assets and needs, is a prerequisite for an accurate choice of interface terms. As regards the field of environmental economics, we have insisted that the interface terminology in English will depend on the users-native born or foreign students, students or 
translators, second-year or post-graduate students, students of economics or students involved in environmental studies. This suggests an answer to the second problem raised at the beginning of this study: ready-made lists of interface terms cannot be drawn. Flexibility is a necessary characteristic of interface terminology and a guarantee that specific goals will be met in the best possible conditions.

Although the problem of interface can be raised in any language, the public we had in mind when investigating this field was primarily one of users of ESP as a foreign language - translators, interpreters, technicians and terminologists, as well as the numerous specialists and scientists who, in their own spheres of activity, resort to English for writing articles or giving lectures in international contexts. We hope that some of our remarks will help them to deal with the intricate problem of achieving the best possible_-or rather the most helpful—selection of interface terms.

\section{APPENDIX 1}

\section{Conceptual Map of Environmental Economics}

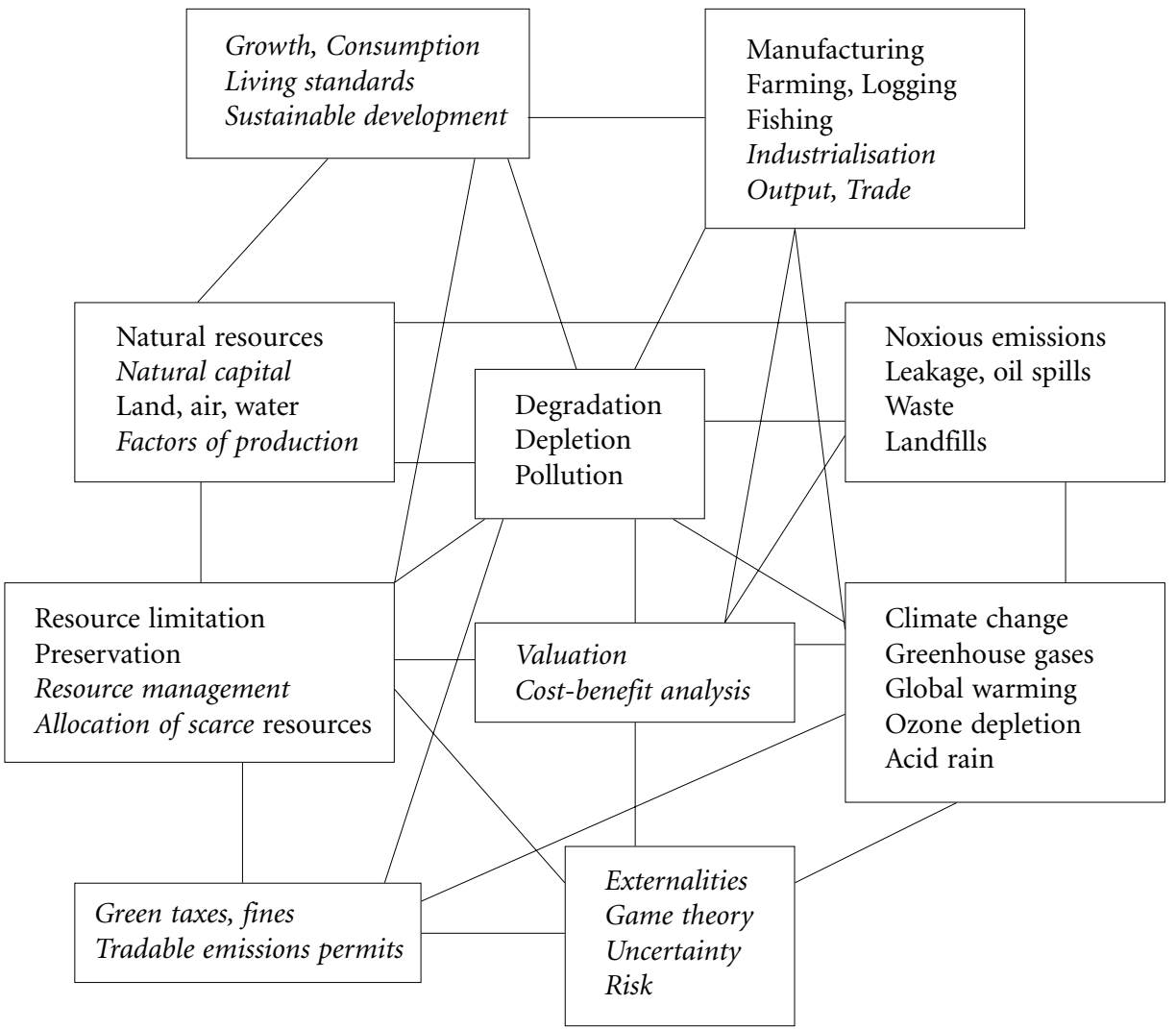




\section{APPENDIX 2}

\section{Initial List of Interface Terms}

Agribusiness

Allocation of scarce resources

Appropriable resources

Certified tradable offsets (CTOs)

Carbon bonds

Clean-up costs

Development economics

Eco-auditing

Eco-duties

Eco-efficiency

Eco-friendly products

Eco-friendly profits

Eco-labelling

Ecological economics

Emission fees

Emissions credits

Emissions permits

Emissions rights

Emission trading

Energy tax

Environmental costs and benefits

Environmental externalities

Environmental taxes

Environmental valuation

Garbage pricing

Green accounting

Green advertising
Green consumerism

Green GDP

Green industry

Green premium

Green tax

Inappropriable resources

Industrial ecology

Life-cycle analysis

Log exports

Marketable pollution rights

Natural capital

Nonrenewable resources

Pollution game theory

Renewable resources

Resource accounting

Resource economics

Resource management

Road pricing

Sustainable economic development

Sustainable economic growth

Sustainable management

Timber trade

Tradable pollution permits

Triple bottom line

Waste accounting

Waste-treatment bills

\section{APPENDIX 3}

\section{Titles of Recent Books on Environmental Economics}

- Biodiversity Conservation and Sustainable Development

- Bioeconomics and Sustainability

- Controlling Pollution in Transition Economies

- Development and Growth Economics

- Ecological Economics

- Economic Growth and the Environment

- Economic Valuation of the Environment

- Economics of Ecological Resources

- Economy and Ecosystems in Change

- Environment and Development Economics

- Environmental Accounting

- Environmental and Resource Economics

- Environmental Valuation

- Fiscal Policy and Environmental Welfare

- Game Theory and the Environment

- Global Development Economics

- Green Accounting in Europe

- Green Taxes

- Industrial Ecology
- International Competitiveness and Environmental Policies

- Measuring Sustainable Development: Macroeconomics and the Environment

- Natural Resource and Environmental Economics

- Pollution and the Firm

- Pollution for Sale

- Private Capital Flows and the Environment

- Resource Management

- The Economic Valuation of Landscape Change

- The Economics of Deforestation in the Ecuadorean Highlands

- The Economics of Emission Trading

- The Economics of Environmental Degradation / Protection / Risk

- The Economics of Wetlands, Wildlands and Biodiversity

- The Greening of Manufacturing

- The Waste and the Backyard

- Trade and the Environment 


\section{APPENDIX 4}

\section{A/ Additional Terms and Phrases corresponding to the 2 nd sphere}

Acid rain
Agro-chemicals
Biodegradable
Biodiversity
Bioeconomics
Bioengineer
Bioengineering
Carbon dioxide $\left(\mathrm{CO}_{2}\right)$
Chlorofluorocarbons $(\mathrm{CFCs})$
Contaminants
Deforestation
Depletion
Ecosystem
Effluent
Exhaust pipes
Extinction
Farming
Fertilisers
Fossil fuels
Fumes

\section{Phrases}

Agricultural land

Alternative energy

Carbon absorption capacity

Climate change

Continental drying

Cost-effective emission reduction strategies

Cross-border pollution

Desertification of once arable land

Endangered species

Energy conservation / storage

Environmental degradation / ills

Environmental preservation / protection

Exhausted ocean fishing grounds

Forest management

Habitat destruction

Pollution abatement / control

Pollution-control devices

Pollution-intensive companies

Recycling systems

Replenishable energy sources

Reusable energy

Sea-level rise

Shifting currents

Substitute energy

Waste disposal

To address environmental issues

To call for a halt to logging
Global warming

Greenhouse effect

Landfill

Leaded petrol / Lead-free petrol

Leakage

Mineral resources

Nuclear waste

Ozone hole

Ozone layer / shield

Overfishing

Pollutant

Polluter

Polar ice cap

Recyclable

Recycled paper / pulp

Reforestation

Spill

Solar energy

Substitutability

Wind power

To cap overall emissions

To commercialize environmentalism

To compile a life-cycle analysis

To chop down trees

To clean up one's act

To dampen energy use

To dump toxic waste in landfills

To eat a hole in the ozone layer

To embrace environmental goals

To determine the most profitable pollution level / rate

To foul the water

To mar the landscape

To pay off on the bottom line

To phase out ozone-depleting chemicals

To poison the air

To preserve the habitat of ...

To produce ... in a least-cost manner

To root out polluting processes

To trash the environment

To reduce hazardous waste

To replant a logged-out forest

To sort the garbage

To spew out noxious fumes

To threaten ... with extinction

To trap heat in the atmosphere

To turn eco-friendliness into a cost advantage

To wipe out an entire species 


\section{B/ Examples of Additional Terms and Phrases Corresponding to the Outer Spheres}

\section{On the problem of "greening" a business}

Asset recycle management plans

Chain saws lubricated with vegetable oil

Cradle-to-cradle analysis

Cradle-to-grave analysis

De-sulphurisation equipment

End-of-pipe abatement / control / solutions

Environmentally-benign technology

Prepaid return labels

Refillable containers

Retooling of the company's processes

Solar-powered lawn mowers

\section{On Agriculture and Forestry}

Accumulative chemicals

Accumulation of pesticides in groundwater

Agricultural GM-free zone

Biodegradable herbicides

Biodiversity conservation / loss

Dioxine-contaminated chicken

Forest clearance

'Frankenstein foods'

Foods free of genetically-modified organisms

Genetically-modified crops

Herbicide-resistant soybeans

Hormone-fed beef

Incendiary farming and grazing practices

Mad-cow disease

Monoculture plantation

Old-growth forests

\section{On energy sources}

Biomass

Geothermal power

Hydropower

Landfill gas

Multicrystal-silicon solar cell

Photovoltaics (PV)
Smoke-belching smelters

Water-saving washing machines

To belch sulphur

To pass energy, wastewater and products back and forth between companies

To recycle plastic bumpers into taillight

housings

To take back packaging

To redesign products

To turn power-plant ash into gypsum board

Pesticide avoidance

Pesticide-treated seeds

Rain-washed topsoil

Receding water tables

Repository of biological diversity

Save-the-forest schemes

To clear land for pasture / for planting

To combat the wheat bulb fly

To drain wetlands

To label GM foods

To plough up heaths

To spray pesticides / insecticides

To uproot hedges

Wilderness areas

Wildlife reserves

Solar-derived hydrogen fuel

Solar panels

Tidal power

Waste-to-energy

Wind farms

Wind turbines 


\section{NOTES}

1. "Resources are called appropriable when firms or consumers can capture their full economic value." Samuelson gives the example of fertile agricultural land, of mineral resources like oil and gas, and of trees. "In a well-functioning, competitive market," he points out, "appropriable resources are usually priced and allocated efficiently." (Samuelson 1998: 326)

2. "An inappropriable resource is one whose use is free to the individual, but costly to society. Inapropriable resources are ones involving externalities." (Samuelson 1998: 326)

3. "Renewable resources, if properly managed, can yield useful services indefinitely." Solar energy, agricultural land, river water, forests and fisheries are among the most important categories of renewable resources. (Samuelson 1998: 326)

4. "A non renewable resource is one that is fixed in supply and which is not regenerated quickly enough to be economically relevant. Examples are fossil fuels and non-uel mineral resources, such as copper, silver, gold, stone and sand." (Samuelson 1998: 326)

5. "Externalities are situations in which production or consumption imposes uncompensated costs or benefits on other parties." If a firm dumps a toxic chemical into a stream and fouls the water for the fishermen and swimmers downstream, it generates an external diseconomy: it uses scarce clean water without paying those whose water is fouled. (Samuelson 1998: 326)

6. "Public goods are ones whose benefits are indivisibly spread among the entire community, whether or not individuals wish to buy them." Government action is often necessary to ensure efficient provision of public goods. (Samuelson 1998: 331)

7. "Private goods are ones that can be divided up and provided separately to different individuals." Markets can allocate private goods efficiently. (Samuelson 1998: 331)

8. "In this approach, a reasoned decision process involves listing the events that may occur, estimating the consequences of the events, judging the probability of the occurrence of each event, weighing the expected value of the consequences against the expected costs under different courses of action, and choosing the action that minimises the expected value or utility of the outcome." (Samuelson 1998: 339)

9. Under the system of tradable emissions permits, the government chooses the level of pollution and allocates the appropriate number of permits. Firms are then allowed to buy and sell the permits. If firms can reduce their noxious emissions cheaply, they do so and sell their permits to those who need additional permits for new plants or find it more economical to buy permits than to install expensive anti-pollution equipment. This approach can of course be conceived on a global scale. (Samuelson 1998: 337)

\section{REFERENCES}

Arntz, R. (1981): "terminology as a discipline in the training of translators and interpreters in language for special purposes," Theoretical and Methodological Problems of Terminology, Munich, K. G. Saur Verlag, coll. “Infoterm”, no 6, pp. 524-530.

Damaso, E. (1996): «Le traducteur face à un domaine spécialisé», Asp, 11-14, La Revue du Geras, Bordeaux, Université V. Segalen-Bordeaux II, p. 181-194.

Drozd, L. (1981): "Some Remarks on a Linguistic Theory of Terminology," Theoretical and Methodological Problems of Terminology, Munich, K. G. Saur Verlag, coll. “Infoterm”, nº, pp. 106117.

Dubuc, R. (1981): «La situation en terminologie», Theoretical and Methodological Problems of Terminology, Munich, K. G. Saur Verlag, coll. “Infoterm”, nº 6, pp. 571-582.

Felber, H. (1981): “The Vienna School of Terminology Fundamentals and its Theory," Theoretical and Methodological Problems of Terminology, Munich, K. G. Saur Verlag, coll. "Infoterm", $\mathrm{n}^{\circ}$ 6, pp. 69-86.

Folmer, H. and T. Tietenberg (1997): The International Yearbook of Environmental and Resource Economics, Colby College (US), Edward Elgar Publishing.

Gouadec, D. (1997): Terminologie et phraséologie pour traduire, Paris, La Maison du Dictionnaire.

Humbley, J. (1998): «Le terminologue et le spécialiste de domaine», Asp 19-22, La Revue du Geras, Bordeaux, Université V. Segalen-Bordeaux II, p. 19-22. 
Lerat, P. (1997): "Approches linguistiques des langues spécialisées», Asp 15-18, La Revue du Geras, Bordeaux, Université V. Segalen-Bordeaux II, p. 1-10.

Resche, C. (2000): "Equivocal economic terms or terminology revisited," Meta, 45-1.

WÜstER, E. (1979): Einführung in die allgemeine Terminologielehre und terminologische Lexikographie, 2 vol., New York, Springer.

\section{ADDITIONAL REFERENCES}

Publishers' catalogues (1997 and 1998)

Ashgate, Aldershot, Hampshire, UK. Blackwell, Oxford, UK; Malden, MA, US.

Cambridge University Press, Cambridge, UK.

Edward Elgar Publishing Limited, Glos, UK; Cheltenham, MA, US.

Jai Press Inc., Greenwich, CT, US. Jai Press Ltd, London, UK.

Kluwer Academic Publishers, Dordrecht, The Netherlands.

Macmillan, Basingstoke, Hampshire, UK. 